\title{
FANCA Biallelic Inactivation
}

National Cancer Institute

\section{Source}

National Cancer Institute. FANCA Biallelic Inactivation. NCI Thesaurus. Code C150583.

The presence of mutations in both alleles of the FANCA gene that either lead to loss of expression of the FANCA protein or result in the translation of an inactive FANCA protein. 